This item was submitted to Loughborough's Research Repository by the author.

Items in Figshare are protected by copyright, with all rights reserved, unless otherwise indicated.

\title{
Assessing aspects of children's written grammar: automating the process
}

PLEASE CITE THE PUBLISHED VERSION

PUBLISHER

(C) Elsevier

LICENCE

CC BY-NC-ND 4.0

REPOSITORY RECORD

Holdich, C.E., R.G. Holdich, and Paul Wai Hing Chung. 2006. "Assessing Aspects of Children's Written Grammar: Automating the Process”. figshare. https://hdl.handle.net/2134/2351. 
This item was submitted to Loughborough's Institutional Repository by the author and is made available under the following Creative Commons Licence conditions.

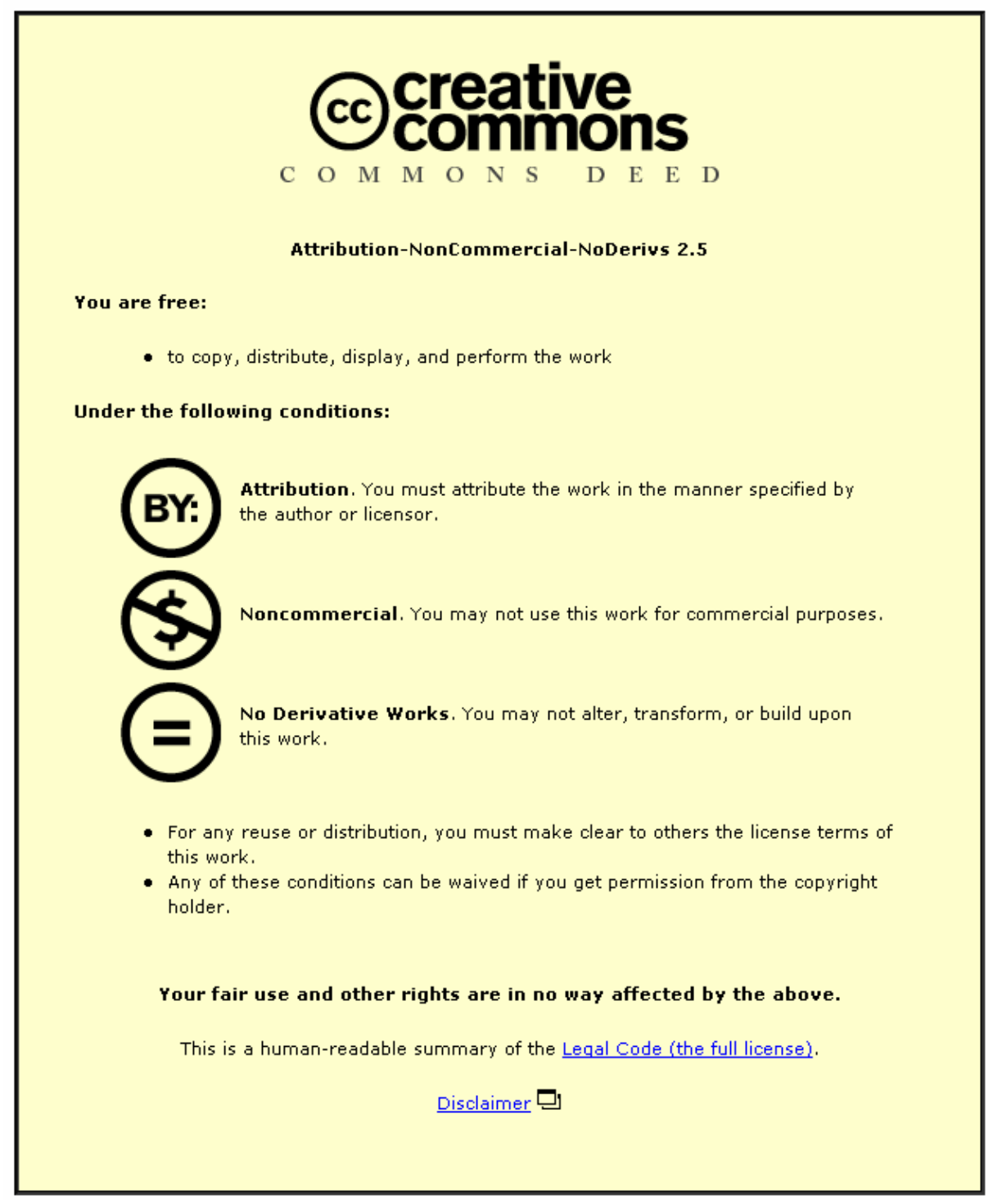

For the full text of this licence, please go to: http://creativecommons.org/licenses/by-nc-nd/2.5/ 


\title{
Assessing aspects of children's written grammar: automating the process
}

\author{
C.E. Holdich, R.G. Holdich and P.W.H. Chung \\ Department of Computer Science \\ Loughborough University
}

\begin{abstract}
Teachers are expected to make regular assessments of pupils' writing, providing feedback about their strengths and weaknesses. If the computer could assist teachers in this task by effectively analysing the grammar element in children's writing, then the teacher's work load would be significantly reduced. A computer generated 'text analysis' of grammatical features would have the benefit of providing diagnostic information systematically and efficiently. Although text analysis is not new, it is generally restricted to applications aimed at adults. The development of a quantitative text analysis program, specifically geared to analysing children's writing was therefore considered profitable. This required an understanding of the development of children's writing abilities and the criteria of the National Curriculum levels of attainment for the Standard Assessment Tasks (SATs). Ten grammar features were selected for analysis. Stories reflecting the spread of attainment associated with the end of Key Stage 2 were analysed. The computer successfully distinguished positive and negative grammar features within these texts. Nevertheless, an assessment of qualitative genre details made by teachers will still be required, in order to provide a balanced assessment which includes all elements that contribute to effective writing.
\end{abstract}

Keywords: elementary education; evaluation methodologies; improving classroom teaching

\section{Introduction}

The British Government has set 'a challenging national target' for pupils in Literacy (www.standards.dfee.gov.uk/performance). Eighty per cent of 11 year olds are expected to achieve 'Level 4' or above in National Curriculum tests known as Standard Assessment Tasks (SATs) taken at the end of Key Stage 2. In both the 2000 and 2001 tests, $75 \%$ of 11 year olds achieved this minimum level of literacy. However a breakdown of the figures reveals that, although $82 \%$ of 11 year olds achieved Level 4+ in reading in the 2001 tests, only 58\% achieved the same level in writing. Assisted by government documents, primary teachers are required to further develop their pupils writing skills if the target is to be met. English: The 
National Curriculum for England (DfEE, 1999) identifies the levels of attainment. The National Literacy Strategy (DfEE, 1998) outlines teaching objectives for each of the year groups within the Key Stage. Teachers are expected to use the Literacy Strategy teaching objectives to help their pupils move from one National Curriculum level to the next.

An integral part of the process of teaching writing is the regular assessment of pupils' writing skills, which involves marking scripts and providing pupils with feedback about their performance. Marking guidelines for writing (2001) encourages teachers to make detailed assessments of individual pupil's strengths and weaknesses. Teachers are expected to use a process similar to the mark scheme used to assess the writing element of the SATs at the end of Key Stage 2. This assessment is divided into two aspects: organisation and grammar (including punctuation). Briefly, to achieve Level 4, writing should be coherent and well paced, with a beginning middle and end suitably distinguished and events logically related, with some interaction between characters. Writing should also demonstrate: mostly correct use of full stops (including question and exclamation marks); some evidence of the correct use of commas to separate clauses and short phrases; some grammatically complex sentences, showing different types of connectives; some adventurous vocabulary (including adverbial and noun phrases) and consistent use of tenses.

Knowledge of individual children's strengths and weaknesses can indicate which aspects require further practice. However, whilst assessing the organisation element of story writing is arguably straightforward, undertaking detailed analyses of children's grammar is a time consuming task which requires a comprehensive knowledge of grammar not necessarily possessed by teachers. If the assessment of children's grammar could be successfully automated by the computer, in the form of a text analysis program, then the teacher's feedback to pupils about their writing performance might be more effective, whilst their workload would be considerably reduced.

Text analysis programs already exist, but they are targeted at the way adults write rather than children. Two questions required consideration when programming a computer to analyse children's writing: which grammar features can be successfully detected by the computer and do these features demonstrate the difference between effective and poor writing skills? Based on the SATs grammar requirements, and research concerning children's grammar and punctuation development, ten linguistic features; covering sentence construction, vocabulary 
and punctuation, were chosen for investigation. Stories reflecting the spread of attainment levels of 11 year old pupils were analysed by the computer to determine whether trends between the national curriculum levels could be detected in these features. The statistical analysis was compared to a human interpretation of the syntactical patterns that contributed to the effectiveness of each text in order to understand the significance of the findings. The outcome was a formative set of results which could form the basis of a diagnostic tool for teachers, geared specifically for story writing at Key Stage 2.

\section{Children's linguistic development}

This literature review is restricted to research underpinning the national documents, which identifies children's linguistic development. For information about the mental processes that affect writers' behaviour, the interested reader is directed to the work of, for example; Flower and Hayes (1981), Graves (1983), Bereiter and Scardamalia (1987), and Sharples (1999).

\subsection{Vocabulary and syntax development}

Drawing upon Quirk's (1972) descriptive grammar, Perera (1984) and Kress (1982,1994) have established several broad stages of linguistic development which children ensue as they develop into mature writers, although they hold different views concerning the reason for this common pattern of development. Perera perceived that children's writing development is influenced by the models of writing presented to them in published texts: as children grow older, the texts they read contain more mature writing styles, which are imitated by children in their writing. Kress identified the presence of maturity in writing when children learn to write sentences which display a different syntax to speech.

Briefly, the pattern of development proceeds broadly as follows. Initially, children characteristically write a few lines of text using simple vocabulary such as 'big', 'nice', 'said', 'went', 'saw', 'got' etc., recording their thoughts and ideas in simple sentences. Young children frequently exhibit excessive repetition of the same subject pronoun such as I...I...I or He...He...He. This reflection of the characteristic chaining syntax of speech results in a rather tedious writing style. Compound sentences are also a feature of early writing development. Typically, sentences are linked by several 'and's or 'and then's. For example: 'I went to the park and I fed the ducks and I went on the swings and then I went on the slide'. A more mature style develops as more sophisticated vocabulary is incorporated such as 'enormous', 'beautiful', 'whispered', 'ambled', 'fetched' etc. and when adverbs such as 'nearly' or 'quietly' 
are chosen to convey shades of meaning. Other ways of writing sentences begin to be applied, such as replacing an 'and' with a full stop and beginning a new sentence, or substituting an alternative connective for 'and' such as 'when' or 'whilst'. Thus, the phrase 'the wind blew and the leaves fell from the trees' might be expressed by a more mature writer as 'when the wind blew, the leaves fell from the trees'. As children's use of compound sentences decreases, so their use of complex sentences, where an independent (main) clause is linked to dependent (subordinate) clauses, increases. Mature writing is thus characterised by the presence of subordinated and embedded clauses. Therefore a young child might write: 'She ran quickly to get to the shop before it closed', whilst a mature writer might record the event as 'Running quickly, she reached the shop before it closed'. According to Perera, up to the age of nine years, most children display a lower level of grammatical maturity in their writing than in their speech. From then on, writing becomes increasingly differentiated from spoken language, employing a higher proportion of complex constructions and structures that rarely occur at all in spontaneous speech, which Perera suggests is influenced by reading. However, although linguistic maturity can be seen in terms of the writer's increasing ability to handle complex constructions successfully and immaturity evidenced by a succession of short simple sentences, mature writers recognise that there is no virtue in complexity for its own sake. Short, simple sentences should be interspersed between longer, more complex sentence constructions when writing a story, to achieve particular effects - short sentences can add suspense whilst long sentences comprised of several clauses, can enhance descriptions.

\subsection{Punctuation}

Punctuation is directly linked to grammar, as it is the purpose of punctuation to enable texts to be read coherently by displaying their grammatical structure. The key features are the sentence ending points and clause dividing commas (Crystal, 1995, p.278). There has been little research into how punctuation is learned however - few studies have attempted to make comparisons over time to discover how use of punctuation develops, as most studies feature beginner writers, whether adults or children (e.g. Shaughnessy 1977, Edelsky 1983). As Hall and Robinson (1996, p.1) commented, 'the demands of the British National Curriculum documents were predicated upon virtually no research evidence'. However, the studies that have been undertaken, agree that understanding the punctuation system is a slow process because punctuation is a complex object. The central problem is that although 'a sentence' is readily defined by linguists, children have no notion of the concept of 'a complete sentence' (Hall, 1996). Kress (1994) suggests the cause of this problem: children spend the first few 
years of life in a world which is highly oral. The sentence is a unit of written language, not spoken, of which young children have little experience.

Hall (1996) has noted how the studies investigating children's punctuation are unrelated pieces of research, which do not form a coherent picture. Nevertheless, some interesting observations have been made. Early writing by children is characterised by the absence of the sentence (Kress, 1982). If full stops are used, they are likely to be used to separate more easily understood units such as lines, pages or subjects. Cazden et al. (1985) found five patterns of usage when children begin to use punctuation: interword, endline, endpage, phrase structure and correct usage, but more than one of these hypotheses were tried in a single story by all the children studied. Cordiero (1988) noted older children made phrasal misplacement errors, whereas younger children made errors related to lineness, wordness and pageness rather than syntactic categories. Wilde's (1996) two year study, restricted to the development of just four punctuation marks, (full stops, question marks, commas and speech marks) revealed that children initially focus their efforts on full stops, then pay increasing attention to question marks, followed by commas, then speech marks. Anderson (1996) found that seven year old children are more consistently accurate in their use of punctuation when their writing is restricted to simple sentences, than when they attempt more complicated sentence constructions. Hall (1998) found that six year old children are resistant to using punctuation, particularly full stops, despite regular reminders to include punctuation, suggesting that punctuation is meaningless to very young writers.

\section{Text Analysis Programs}

An analysis of the features contained within existing text analysis programs was necessary to help identify appropriate features. Applications such as 'Writer's Helper for Windows' (1992) carry out objective, statistical analyses of features such as word frequencies and sentence lengths. The applications are targeted at adults however, who are expected to be already highly competent at writing, as they highlight for instance: split infinitives, sentences longer than 50 words, weak phrases, percentage of abstract words, percentage of passive sentences and readability scores, as do modern word processors. Writers are expected to interpret the significance of the statistics, using the information to improve their texts accordingly. Text analysis is usually regarded as unsuitable for children however, as much of the available statistical information is inappropriate and the method of presentation is likely to be meaningless to them. A statistical analysis of stories written by children could be of benefit 
to teachers and ultimately to pupils however, if the features analysed were made specifically relevant to children's writing and if the analysis was presented in a way that is meaningful. The question that required consideration was: what information would be useful to teachers and children? An analysis of stories written by children was required to demonstrate which grammar features could be successfully and usefully detected by computer.

\section{The study}

\subsection{Method}

An analysis was performed upon a small sample of 12 stories written by Year 6 children (aged 11) for the SATs writing test. The stories were obtained from two publications, provided by The Stationery Office $(1997,1998)$ as examples of the different standards of attainment associated with the end of Key Stage 2. Table 1 shows the range of levels of the sample texts.

Table 1. Examiners' assessment of sample children's stories from Key Stage 2 National Curriculum Tests

\begin{tabular}{|l|c|c|c|c|c|c|c|c|c|c|c|c|}
\hline $\begin{array}{l}\text { Story } \\
\text { number }\end{array}$ & $\mathbf{1}$ & $\mathbf{2}$ & $\mathbf{3}$ & $\mathbf{4}$ & $\mathbf{5}$ & $\mathbf{6}$ & $\mathbf{7}$ & $\mathbf{8}$ & $\mathbf{9}$ & $\mathbf{1 0}$ & $\mathbf{1 1}$ & $\mathbf{1 2}$ \\
\hline Score & 10 & 17 & 20 & 21 & 24 & 25 & 26 & 28 & 30 & 32 & 33 & 35 \\
\hline $\begin{array}{l}\text { N.C. } \\
\text { Level }\end{array}$ & $2 \mathrm{c}$ & $3 \mathrm{~b}$ & $3 \mathrm{a}$ & $4 \mathrm{c}$ & $4 \mathrm{~b}$ & $4 \mathrm{a}$ & $4 \mathrm{a}$ & $5 \mathrm{c}$ & $5 \mathrm{~b}$ & $5 \mathrm{a}$ & $5+$ & $5+$ \\
\hline
\end{tabular}

These examples were chosen for analysis because they had been objectively marked by official examiners who had selected them as suitably representative of the different national curriculum levels. The most significant and unique feature of the sample, was the availability of detailed written comments from the assessors which highlighted why each story achieved a particular level. The sample was limited in size because these stories are the only test examples currently publicly available that are accompanied by such written comments. Despite its small size, the sample was considered useful for a formative study to establish a methodology which could indicate strengths and weaknesses in children's written grammar. The benefit of performing a computer statistical analysis on this particular collection of stories was that the computer analysis could be compared to a reliable and objective human interpretation. A possible outcome of the study could be a proposal to conduct further analysis 
of a larger number of stories, which could be developed into a more comprehensive text analysis program geared specifically to children's narrative writing.

\subsection{Features of writing selected for analysis by the computer}

Based on the findings of the research already referenced and upon a selection of features covering vocabulary, syntax and punctuation, outlined in the National Curriculum levels, ten indicators of language skill were chosen for analysis. A 'Check Text' program, written in Visual Basic Script, was created to supply statistical information about each text. The information was then compared to the examiner's interpretation of the syntactical patterns that contributed to the effectiveness of the text. Underpinning this study is the understanding that children's writing develops at different rates along the different dimensions. An increase in vivid vocabulary for instance, may not be accompanied by a similar growth in ability of handling a range of sentence structures. Thus, several strands of language were selected for this investigation.

The ten indicators were:

1. The total length of the story (in words);

2. The number of different words used in the first 100 words;

3. Common verbs used (said, went, got, get, was, were) as a percentage of total number of words;

4. Number of different words with more than 5 characters as a percentage of total words;

5. Number of adverbs as a percentage of total words.

6. The number of 'and's used as a connective as a percentage of the total words;

7. Basic common connectives (but, so, then, because) as a percentage of the total number of words;

8. The percentage of sentences started with basic words (personal pronouns, and the definite article);

9. Mean sentence length;

10. Commas used as a percentage of mean sentence length, as a measure of the presence of clauses. 


\section{Results}

\subsection{Comparison of output}

The results of the comparison of output from the sample stories, as shown in Table 2, indicate that the length of a story correlated successfully with the level of attainment achieved: the longer the story, the higher the level achieved. It would appear that a minimum of approximately 300 words is required to explain a story in sufficient detail in order to gain Level 4, whilst the ability to write approximately 400 words, or more, is likely to achieve Level 5. This is clearly the least satisfactory of the ten indicators, but the trend is obvious.

Table 2. Number of words in stories in sample stories at the end of Key Stage 2

\begin{tabular}{|l|c|c|c|c|c|c|c|c|c|c|c|c|}
\hline $\begin{array}{l}\text { Story } \\
\text { number }\end{array}$ & $\mathbf{1}$ & $\mathbf{2}$ & $\mathbf{3}$ & $\mathbf{4}$ & $\mathbf{5}$ & $\mathbf{6}$ & $\mathbf{7}$ & $\mathbf{8}$ & $\mathbf{9}$ & $\mathbf{1 0}$ & $\mathbf{1 1}$ & $\mathbf{1 2}$ \\
\hline $\begin{array}{l}\text { National } \\
\text { Curriculum } \\
\text { Level }\end{array}$ & $\mathbf{2 c}$ & $\mathbf{3 b}$ & $\mathbf{3 a}$ & $\mathbf{4 c}$ & $\mathbf{4 b}$ & $\mathbf{4 a}$ & $\mathbf{4 a}$ & $\mathbf{5 c}$ & $\mathbf{5 b}$ & $\mathbf{5 a}$ & $\mathbf{5 +}$ & $\mathbf{5 +}$ \\
\hline Total words & 228 & 289 & 246 & 380 & 316 & 364 & 385 & 400 & 394 & 447 & 608 & 829 \\
\hline
\end{tabular}

\subsection{Vocabulary}

Four tests were devised to detect variety and the presence of simple and sophisticated vocabulary.

\subsubsection{Variety of vocabulary}

Harpin's (1976) technique for testing for the variety of vocabulary contained within texts written by children of different ages was applied and extended. This involved expressing the number of different words used (type) as a proportion of the total number of words (tokens), producing a type-token ratio (TTR). For example, a paragraph containing 100 words could contain 65 different words. This would give a ratio of 0.65. Like Harpin, the TTR was calculated for the first 100 words of each of the 12 stories. The results are recorded in Table 3.

Table 3. Harpin's Type Token Ratio (TTR) for the sample stories

\begin{tabular}{|l|c|c|c|c|c|c|c|c|c|c|c|c|}
\hline $\begin{array}{l}\text { Story } \\
\text { number }\end{array}$ & $\mathbf{1}$ & $\mathbf{2}$ & $\mathbf{3}$ & $\mathbf{4}$ & $\mathbf{5}$ & $\mathbf{6}$ & $\mathbf{7}$ & $\mathbf{8}$ & $\mathbf{9}$ & $\mathbf{1 0}$ & $\mathbf{1 1}$ & $\mathbf{1 2}$ \\
\hline $\begin{array}{l}\text { National } \\
\text { Curricul } \\
\text { um Level }\end{array}$ & $\mathbf{2 c}$ & $\mathbf{3 b}$ & $\mathbf{3 a}$ & $\mathbf{4 c}$ & $\mathbf{4 b}$ & $\mathbf{4 a}$ & $\mathbf{4 a}$ & $\mathbf{5 c}$ & $\mathbf{5 b}$ & $\mathbf{5 a}$ & $\mathbf{5 +}$ & $\mathbf{5 +}$ \\
\hline TTR & 0.54 & 0.60 & 0.61 & 0.65 & 0.68 & 0.66 & 0.59 & 0.68 & 0.61 & 0.73 & 0.75 & 0.65 \\
\hline
\end{tabular}


Broadly, the lower levels of attainment resulted in low TTR ratios whilst the higher levels of attainment resulted in higher TTR ratios, although the results inevitably deviated on occasion depending on the strengths and weaknesses of the particular young writer and on the theme and organisation of the story. The figures reflected the comments made by the examiners: the variety of vocabulary in stories 10 and 11 (with a TTR of 0.73 and 0.75 respectively) were especially commented on, whilst the lack of variety or frequent repetition in stories 1 and 2 (with a TTR of 0.54 and 0.60) was also noted. Stories 5 and 8, with a TTR of 0.68 , received comments such as 'some well chosen vocabulary'. Harpin (1976) suggested that the sharper the drop in TTR after the first 100 words, the less diverse a child's vocabulary resources were likely to be. The drop in TTR after each subsequent 50 words for all the stories was therefore recorded and plotted in order to determine whether the rate of drop correlated with the levels of attainment. The graph was then normalised with respect to the initial value to illustrate more clearly the rate of drop and this is presented in Figure 1.

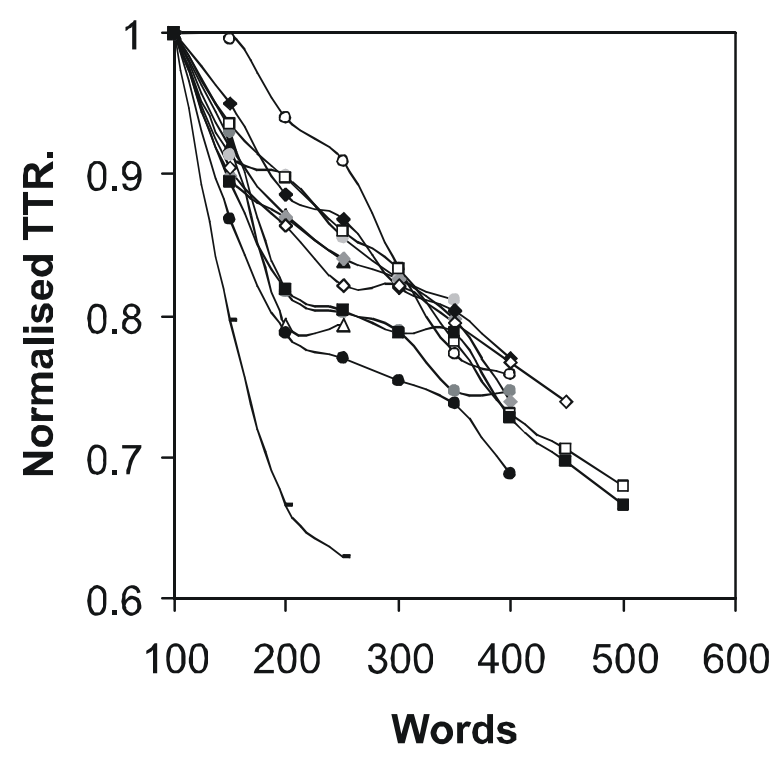

$$
\begin{array}{llllll}
-2 & -3 & -4 & \rightarrow 4 & -5 & \rightarrow 5 \\
-3 & -4 & -4 & \rightarrow 5 & -5+ & -5+
\end{array}
$$

Figure 1. Reduction in Harpin's Type Token Ratio for words used after the first 100 
Whilst the TTR for the story achieving Level 2 dropped sharply, there was little to discriminate between the other levels. Although Harpin was correct in his hypothesis that the rate of fall in the TTR would reveal the extent of variety of a child's vocabulary, the results did not prove useful in a quantitative analysis of the various levels. The TTR of the first 100 words gave the clearest indication of the diversity of a child's vocabulary resources.

\subsubsection{Common verb forms}

As simple verbs such as said, went, was, were, got and get are commonly used by young, beginner writers, it was anticipated that children achieving higher levels would demonstrate their ability to express themselves clearly through the use of alternative verbs to said, went, etc. in order to describe actions precisely. The percentage of words used, which were common verbs, was therefore calculated and is presented in Table 4.

Table 4. Number of common verbs used as a percentage of total words for the sample stories

\begin{tabular}{|l|c|c|c|c|c|c|c|c|c|c|c|c|}
\hline $\begin{array}{l}\text { Story } \\
\text { number }\end{array}$ & $\mathbf{1}$ & $\mathbf{2}$ & $\mathbf{3}$ & $\mathbf{4}$ & $\mathbf{5}$ & $\mathbf{6}$ & $\mathbf{7}$ & $\mathbf{8}$ & $\mathbf{9}$ & $\mathbf{1 0}$ & $\mathbf{1 1}$ & $\mathbf{1 2}$ \\
\hline $\begin{array}{l}\text { National } \\
\text { Curricul } \\
\text { um Level }\end{array}$ & $\mathbf{2 c}$ & $\mathbf{3 b}$ & $\mathbf{3 a}$ & $\mathbf{4 c}$ & $\mathbf{4 b}$ & $\mathbf{4 a}$ & $\mathbf{4 a}$ & $\mathbf{5 c}$ & $\mathbf{5 b}$ & $\mathbf{5 a}$ & $\mathbf{5 +}$ & $\mathbf{5 +}$ \\
\hline $\begin{array}{l}\% \quad \text { of } \\
\text { common } \\
\text { verbs }\end{array}$ & 9.6 & 2.8 & 5.7 & 5 & 4.7 & 4.9 & 4.9 & 3.3 & 5.6 & 4 & 2.3 & 4.7 \\
\hline
\end{tabular}

As expected, story 1, achieving Level 2c had a high dependence on common verbs. Story 2 used surprisingly few. This may have been because the story lacked dialogue with the result that the verb 'said', frequently over used by immature writers, was not used at all. The stories achieving Level $5 \mathrm{c}$ and above, with the exception of stories 9 and 12, showed less of a dependence on the common verbs than the stories achieving the lower levels.

\subsubsection{Word length}

A test was designed which attempted to detect the degree of sophistication of words used, as evidence of mature writing. It assumed that a sign of more sophisticated vocabulary is a frequent use of long words; that is moving away from using simple, short words like 'big' and 'nice', to using more sophisticated, longer words like 'enormous' and 'beautiful'. However, the computer would be unable to distinguish between basic but 'long' words such as 'lovely' or 
'netball', and more adventurous and imaginative vocabulary such as 'glistened' or 'irritating' used to create poetic effects, personification, alliteration, assonance and metaphors etc. Words longer than 5 letters, excluding repeated words, were counted and recorded in Table 5.

Table 5. Words greater than 5 letters used in each sample story as a percentage of total words

\begin{tabular}{|l|c|c|c|c|c|c|c|c|c|c|c|c|}
\hline $\begin{array}{l}\text { Story } \\
\text { number }\end{array}$ & $\mathbf{1}$ & $\mathbf{2}$ & $\mathbf{3}$ & $\mathbf{4}$ & $\mathbf{5}$ & $\mathbf{6}$ & $\mathbf{7}$ & $\mathbf{8}$ & $\mathbf{9}$ & $\mathbf{1 0}$ & $\mathbf{1 1}$ & $\mathbf{1 2}$ \\
\hline $\begin{array}{l}\text { National } \\
\text { Curricul } \\
\text { um Level }\end{array}$ & $\mathbf{2 c}$ & $\mathbf{3 b}$ & $\mathbf{3 a}$ & $\mathbf{4 c}$ & $\mathbf{4 b}$ & $\mathbf{4 a}$ & $\mathbf{4 a}$ & $\mathbf{5 c}$ & $\mathbf{5 b}$ & $\mathbf{5 a}$ & $\mathbf{5 +}$ & $\mathbf{5 +}$ \\
\hline $\begin{array}{l}\text { \% of } \\
\text { words }> \\
5 \text { letters }\end{array}$ & 10.1 & 15.2 & 12.2 & 13.9 & 15.2 & 13.2 & 11.7 & 17.3 & 14 & 21.3 & 18.1 & 13.1 \\
\hline
\end{tabular}

Generally, the results were consistent with the examiners' comments about vocabulary choice. Story 1 for example, was described as containing very simple vocabulary; story 7 was noted for its choice of appropriate vocabulary, whilst stories 5, 6, 8, 10 and 11 were reported to have some well chosen and imaginative vocabulary. Stories 7 and 12 had fewer long words than might be expected for the level achieved, corresponding to relatively few sophisticated words present in their writing. This could indicate a weakness in the writing skills for the young writers concerned, or merely that the writers felt simpler words were appropriate on this occasion.

\subsubsection{Adverbs}

Another aspect of vocabulary growth, is the range of senses which words can communicate. This means taking account of the shades of meaning that can be attributed to words. As the adverbial element in a sentence provides important information about the time, manner, place and reason, of the actions of the verb, a higher proportion of adverbs present in a story could therefore indicate a more sophisticated vocabulary. The percentage of words used in a text which are single word adverbs ending $l y$, is recorded in Table 6.

Table 6. Adverbs used in each sample story as a percentage of total words

\begin{tabular}{|l|c|c|c|c|c|c|c|c|c|c|c|c|}
\hline $\begin{array}{l}\text { Story } \\
\text { number }\end{array}$ & $\mathbf{1}$ & $\mathbf{2}$ & $\mathbf{3}$ & $\mathbf{4}$ & $\mathbf{5}$ & $\mathbf{6}$ & $\mathbf{7}$ & $\mathbf{8}$ & $\mathbf{9}$ & $\mathbf{1 0}$ & $\mathbf{1 1}$ & $\mathbf{1 2}$ \\
\hline $\begin{array}{l}\text { National } \\
\text { Curricul }\end{array}$ & $\mathbf{2 c}$ & $\mathbf{3 b}$ & $\mathbf{3 a}$ & $\mathbf{4 c}$ & $\mathbf{4 b}$ & $\mathbf{4 a}$ & $\mathbf{4 a}$ & $\mathbf{5 c}$ & $\mathbf{5 b}$ & $\mathbf{5 a}$ & $\mathbf{5 +}$ & $\mathbf{5 +}$ \\
\hline
\end{tabular}




\begin{tabular}{|l|l|l|l|l|l|l|l|l|l|l|l|l|}
\hline um Level & & & & & & & & & & & & \\
\hline $\begin{array}{l}\text { \% of } \\
\text { adverbs }\end{array}$ & 0.4 & 0.3 & 1.6 & 1.1 & 1.3 & 0.8 & 0.3 & 0.8 & 1.8 & 2 & 1.8 & 1.6 \\
\hline
\end{tabular}

As might be expected, stories 9-12, achieving Level $5 b$ and above, used the highest proportion of adverbs whilst stories 1 and 2 used the lowest proportion. The effective use of adverbs in stories 9-12, to enhance descriptions, such as ' slowly sank' and 'floating aimlessly' were noted by the examiners. Story 3 revealed a surprisingly high proportion of adverbs. The examiners noted the beginnings of adventurous language, evidenced by adverbs such as 'eventually', although the majority were basic adverbs such as 'you've only just got here' and 'happily ever after'. Further analysis of story 7 confirmed the lack of adverbs as indicated by the figures, but revealed a greater use of adjectives and adjectival expansion instead such as 'deep, rough sounding voice' which had not been checked for by the computer.

\subsection{Sentence construction}

Two tests were performed to analyse sentence construction: checking for the use of basic sentence connectives and the writer's ability to handle different sentence constructions.

\subsubsection{Connectives}

As beginner writers show a heavy dependence upon the connective 'and' before progressing towards using other basic connectives (so, but, then and because), use of 'and' was investigated separately to the other connectives. The number of times basic connectives are used in a text would be expected to be proportionally fewer in the writing achieving the higher levels, than in the writing achieving the lower levels, as alternative connectives would be present. The number of 'and's in particular would be expected to be highest at the lowest levels. Table 7 records the total percentage of basic connectives to the total number of words for each story together with a breakdown of the percentage of 'and's and other basic connectives.

Table 7. Number of basic connective words used in each sample story as a percentage of total words

\begin{tabular}{|l|c|c|c|c|c|c|c|c|c|c|c|c|}
\hline $\begin{array}{l}\text { Story } \\
\text { number }\end{array}$ & $\mathbf{1}$ & $\mathbf{2}$ & $\mathbf{3}$ & $\mathbf{4}$ & $\mathbf{5}$ & $\mathbf{6}$ & $\mathbf{7}$ & $\mathbf{8}$ & $\mathbf{9}$ & $\mathbf{1 0}$ & $\mathbf{1 1}$ & $\mathbf{1 2}$ \\
\hline $\begin{array}{l}\text { National } \\
\text { Curricul }\end{array}$ & $\mathbf{2 c}$ & $\mathbf{3 b}$ & $\mathbf{3 a}$ & $\mathbf{4 c}$ & $\mathbf{4 b}$ & $\mathbf{4 a}$ & $\mathbf{4 a}$ & $\mathbf{5 c}$ & $\mathbf{5 b}$ & $\mathbf{5 a}$ & $\mathbf{5 +}$ & $\mathbf{5 +}$ \\
\hline
\end{tabular}




\begin{tabular}{|l|c|c|c|c|c|c|c|c|c|c|c|c|}
\hline um Level & & & & & & & & & & & & \\
\hline$\%$ and & 4.8 & 4.8 & 8.5 & 2.1 & 4.4 & 3.3 & 3.6 & 2 & 4.3 & 2.5 & 2 & 2.5 \\
\hline $\begin{array}{l}\text { \% basic } \\
\begin{array}{l}\text { connec- } \\
\text { tives }\end{array}\end{array}$ & 0.9 & 0.7 & 2.4 & 2.9 & 1.9 & 2.5 & 2.6 & 2 & 3 & 0.9 & 2 & 1 \\
\hline Total & 5.7 & 5.5 & 10.9 & 5 & 6.3 & 5.8 & 6.2 & 4 & 7.3 & 3.4 & 4 & 3.5 \\
\hline
\end{tabular}

Broadly, the stories achieving the lower levels showed a dependence on basic connectives, whilst the stories achieving the higher levels revealed less of a dependence. Stories 1 and 2 contained a high percentage of 'and's, also commented on by the examiners, but few common connectives, indicating that these writers had not progressed from the simplest of sentence constructions. Whilst the writing contained in story 3 revealed an over dependence upon the connective 'and', a high percentage of other basic connectives is also evident, indicating that the writer, although immature, was more advanced than the writers of stories 1 and 2. Stories 8, 10, 11 and 12 displayed a lower dependence on basic connectives, as might be expected in writing achieving a high level. Stories 7 and 9 displayed a surprisingly high level of dependence upon basic connectives, indicating a weakness in otherwise effective writing.

\subsubsection{Varying sentence construction}

It was anticipated that immature writers would frequently start sentences in a similar way, but that mature writers would find alternative ways to vary the start of a sentence. A test aiming to check for the writer's ability to handle different sentence constructions, particularly varying the usual starting words for sentences, was devised. It assumed that sentences starting with pronouns (He, She, His, Her, They, We, I), or the definite article are fairly straightforward constructions and likely to be used by immature writers. The proportion of sentences starting with a pronoun or the definite article was therefore checked for in each story, on the assumption that these would be proportionally higher in the stories achieving the lower levels and the results are presented in Table 8.

Table 8. Simple Sentence Starters (SSS) used as a percentage of total number of sentences in each sample story

\begin{tabular}{|l|c|c|c|c|c|c|c|c|c|c|c|c|}
\hline $\begin{array}{l}\text { Story } \\
\text { number }\end{array}$ & $\mathbf{1}$ & $\mathbf{2}$ & $\mathbf{3}$ & $\mathbf{4}$ & $\mathbf{5}$ & $\mathbf{6}$ & $\mathbf{7}$ & $\mathbf{8}$ & $\mathbf{9}$ & $\mathbf{1 0}$ & $\mathbf{1 1}$ & $\mathbf{1 2}$ \\
\hline $\begin{array}{l}\text { National } \\
\text { Curriculu } \\
\text { m Level }\end{array}$ & $\mathbf{2 c}$ & $\mathbf{3 b}$ & $\mathbf{3 a}$ & $\mathbf{4 c}$ & $\mathbf{4 b}$ & $\mathbf{4 a}$ & $\mathbf{4 a}$ & $\mathbf{5 c}$ & $\mathbf{5 b}$ & $\mathbf{5 a}$ & $\mathbf{5 +}$ & $\mathbf{5 +}$ \\
\hline SSS & 0 & 66.7 & 0 & 34.6 & 50 & 31 & 57.1 & 54.5 & 34.8 & 37.2 & 33.3 & 41.5 \\
\hline
\end{tabular}


The results showed that stories 1 and 3 did not use any simple sentence starters. However, story 1 contained only three 'sentences'! Closer inspection of story 3 revealed other simple sentence starters not detected by the test, such as 'so' and 'then', had been used frequently. Stories 2, 7 and 8 showed a heavy dependence on pronouns as a means of starting a new sentence. As stories 7 and 8 achieved a high level, the unusually high percentage of pronouns used at the start of a sentence indicated a weakness in the sentence construction of these particular writers. The lower percentage of simple sentence starters recorded for stories 6,10 and 11 accurately reflected a more varied style, but the low score for story 6 was misleading. The writer had included a high proportion of dialogue; the story was effectively a play script rather than narrative writing, which commands a different writing style.

\subsection{Punctuation}

\subsubsection{Full stops}

An analysis of average sentence length in words was performed (Table 9) in the expectation that it would reveal few instances of insufficient full stops and that these would occur generally at the lower levels.

Table 9. Mean sentence length in words for each sample story

\begin{tabular}{|l|c|c|c|c|c|c|c|c|c|c|c|c|}
\hline $\begin{array}{l}\text { Story } \\
\text { number }\end{array}$ & $\mathbf{1}$ & $\mathbf{2}$ & $\mathbf{3}$ & $\mathbf{4}$ & $\mathbf{5}$ & $\mathbf{6}$ & $\mathbf{7}$ & $\mathbf{8}$ & $\mathbf{9}$ & $\mathbf{1 0}$ & $\mathbf{1 1}$ & $\mathbf{1 2}$ \\
\hline $\begin{array}{l}\text { National } \\
\text { Curricul } \\
\text { um Level }\end{array}$ & $\mathbf{2 c}$ & $\mathbf{3 b}$ & $\mathbf{3 a}$ & $\mathbf{4 c}$ & $\mathbf{4 b}$ & $\mathbf{4 a}$ & $\mathbf{4 a}$ & $\mathbf{5 c}$ & $\mathbf{5 b}$ & $\mathbf{5 a}$ & $\mathbf{5 +}$ & $\mathbf{5 +}$ \\
\hline $\begin{array}{l}\text { Mean } \\
\text { sentence } \\
\text { length }\end{array}$ & 76 & 19.3 & 22.4 & 14.6 & 15.8 & 12.6 & 13.8 & 18.2 & 17.1 & 10.4 & 9.2 & 12.8 \\
\hline
\end{tabular}

The examiners' comments about story 1 concerning a complete lack of punctuation is supported by the analysis of sentence length. Clearly, an average sentence of 76 words has a frequent lack of full stops! The average sentence lengths for stories 2, 3 and 8 are also high. The figures correspond to the examiners' verdict that not all the sentences had been correctly demarcated in these stories. Further analysis of the figures in conjunction with the examiners' comments revealed that the mean sentence length gives more information about sentence construction than at first appears. The low figures for stories 6, 10 and 11 appear to show a 
dependence on simple sentence structure and a lack of variation in sentence length. This was commented upon as a weakness in stories 6 and 11, although the 'short punchy' and 'compact descriptive' sentences in story 10 were an apparent strength. It would seem that an average sentence length of between approximately 12 and 16 words is to be aimed for. This figure will be achieved through a wide variation in individual sentence length however.

\subsubsection{Commas}

As a sign of more advanced writing skills, is the presence of complex sentences and an understanding of the ways commas should be used to punctuate clauses within complex sentences, mature writers would be expected to make a greater use of commas to mark such grammatical boundaries than immature writers. A comparison was therefore made of the number of commas (excluding commas used in lists or numbers) in relation to the average sentence length which is recorded in Table 10.

Table 10. Mean sentence length divided by number of commas for each sample story

\begin{tabular}{|l|c|c|c|c|c|c|c|c|c|c|c|c|}
\hline $\begin{array}{l}\text { Story } \\
\text { number }\end{array}$ & $\mathbf{1}$ & $\mathbf{2}$ & $\mathbf{3}$ & $\mathbf{4}$ & $\mathbf{5}$ & $\mathbf{6}$ & $\mathbf{7}$ & $\mathbf{8}$ & $\mathbf{9}$ & $\mathbf{1 0}$ & $\mathbf{1 1}$ & $\mathbf{1 2}$ \\
\hline $\begin{array}{l}\text { National } \\
\text { Curricul } \\
\text { um Level }\end{array}$ & $\mathbf{2 c}$ & $\mathbf{3 b}$ & $\mathbf{3 a}$ & $\mathbf{4 c}$ & $\mathbf{4 b}$ & $\mathbf{4 a}$ & $\mathbf{4 a}$ & $\mathbf{5 c}$ & $\mathbf{5 b}$ & $\mathbf{5 a}$ & $\mathbf{5 +}$ & $\mathbf{5 +}$ \\
\hline commas & $\infty$ & 4.8 & 11.2 & 3.7 & 0.66 & 1.1 & 1.1 & 1 & 1.3 & 0.3 & 0.2 & 0.4 \\
\hline
\end{tabular}

The method of dividing the mean sentence length by the number of commas was particularly useful for discriminating between the middle and higher levels, although again, deviations from expected scores indicated either a relative strength, or weakness in punctuation for a particular writer. Smaller numbers indicate a more frequent and secure use of commas associated with the higher levels of achievement. Thus, the stories achieving Level 2, 3b, 3a and 4c had a high figure ranging from 11.2 to infinity; the stories achieving Level $4 \mathrm{a}, 5 \mathrm{c}$ and $5 \mathrm{~b}$ had a figure around the number 1 , whilst the stories achieving $5 \mathrm{a}$ and $5+$ had a figure smaller than 1 . In the first three stories, few commas were used to demarcate clauses.

\subsection{Examples of individual story assessments}

Analysing the results for an individual story rather than a particular grammar feature gives a good indication of the level of maturity displayed by the writing. Thus, for example, story 3 
(which achieved Level 3) displayed a low level of maturity as it lacked detail (246 words) and demonstrated a general lack of variety of words (TTR $=0.61)$, although some more sophisticated vocabulary in the form of adverbs (1.6\%) was detected. Immature sentence constructions were evident, demonstrated by a high dependence upon basic connectives (10.9\%), especially 'and' (8.5\%), a high average of words per sentence (22) and a lack of commas demarcating clauses. An average sentence length of 22 words indicated a slightly insecure use of full stops. This grammatical analysis by the computer generally supports the examiners' comments for this story: although the story contained mostly simple adjectives and adverbs, there was evidence of some adventurous vocabulary and some grammatically complex sentences. However, clauses were linked together with mostly simple connectives and only half the sentences were correctly punctuated with full stops. As might be expected, story 10 (which achieved Level 5) was a detailed story (447 words), containing a variety of sophisticated vocabulary $(\mathrm{TTR}=0.73$, words $>5$ letters $=21.3 \%$, adverbs $=1.8 \%$ ). The writer used full stops accurately (mean sentence length $=10.4$ words) and commas to demarcate clauses (0.3). Although the high incidence of commas indicates the presence of complex sentence constructions, the writing lacks a variety of sentence lengths. The low dependence upon basic connectives (0.9\%), including 'and's (2.5\%) is further evidence of mature sentence constructions. Again, the computer analysis supports the examiners' verdict: the story contained mostly correct punctuation, including commas to clarify meanings; varied vocabulary, including patterning, personification and metaphors and a wide variety of sentence structure, including short punchy sentences and compact descriptive sentences.

\section{Conclusions}

It was not the intention of this study to carry out a complete grammatical analysis, but to investigate some of the constructions that provide evidence of differences in maturity in children's writing. A complete linguistic analysis of children's writing by the computer has not been undertaken. Absent, for example, is information about the kinds of subordinate clauses used by the children in their writing and the use made of adjectives and adjectival expansion etc. to achieve particular effects. However, the ten criteria which were selected for investigation, showed evidence as to their value as measures of the strengths, and weaknesses, in the writing of individual children. This formative study demonstrates the potential value of undertaking further research, involving a greater number of stories. 
The results indicate that the computer can identify key differences between mature and immature writing with regard to grammar. Story length correlated most successfully with the national curriculum levels of attainment, although this feature was the least satisfactory. Investigating the percentage of the connective 'and' present in the writing samples successfully highlighted immature writing. By detecting the use of the connective 'and' separately to other basic connectives, it is possible to identify more clearly the stage a writer is at: from complete beginner to an advanced writer. Harpin's TTR method proved a reasonable indicator of vocabulary resources, although analysing the rate of drop in the TTR, after the first 100 words, did not, as hypothesised by Harpin, contribute to the task of differentiating between the levels. The test identifying simple sentence starters would benefit from further refinements. It may prove beneficial to investigate other sentence starters in addition to pronouns and the definite article. Counting sentence lengths in words was reasonably successful at indicating both the insecure and secure use of full stops characteristic of immature and mature writers respectively. In addition, the test indicated the range of sentence constructions evident in a text. However, the most useful test for discriminating the level of maturity in a writing sample was the mean sentence length to comma ratio, indicating the presence of clauses. A writer who is able to correctly punctuate subordinated and embedded clauses contained within complex sentences, is clearly a mature writer.

A computer analysis of samples of writing can thus reveal the level of grammatical maturity the child has reached. Mastery of most grammatical structures is evidence of mature writing pupils achieving the higher national curriculum levels are expected to demonstrate a varied and sophisticated vocabulary, a wide range of sentence constructions and accurate punctuation. However, whilst a statistical analysis of children's written grammar could be useful to teachers, they would also require assistance with interpreting the results, in order to understand their significance. Thus, rather than simply state that the average number of words per sentence is 15 for example, or that basic connectives account for $4.5 \%$ of all words used in a text, information would need to be supplied, stating whether these are desirable features or not.

Writing cannot be assessed by levels of grammatical maturity alone however. Whilst an analysis of particular grammar features can indicate why some texts succeed better than others - a task which can be fulfilled by a computer, it is essential that any assessment considers writing holistically as well. There is little point in a child's story containing mature patterns of 
sentence structure and varied and sophisticated vocabulary, if the writing is boring, lacks organisation and has little plot. Without a holistic assessment, the computer is merely making superficial judgements based on the surface features of a text. Thus, although the computer can assess the level of grammatical maturity in a piece of writing, it is unable to use the information to ascribe national curriculum levels. Nevertheless, a computer analysis of vocabulary use and syntax could be a useful diagnostic tool for teachers who lack the time or necessary linguistic knowledge to undertake the task of careful 'reading' between the words in order to consider the syntactical patterns which contribute to the effectiveness of a text. As The Grammar Papers (1998) concludes, drawing explicit attention of the syntactic features of pupils' writing can increase pupils awareness of how language works, which in turn may increase their control over their writing.

\section{References:}

Anderson, H. (1996) Vicki's story: A Seven -year-old's Use and Understanding of Punctuation. In Hall, N. and Robinson, A. (1996) (eds) Learning about Punctuation (pp. 5463). Multilingual Matters Clevedon, England.

Bereiter, C. and Scardamalia, M. (1987) The Psychology of Written Composition. Lawrence Erlbaum, Hillsdale, New Jersey.

Cazden,C. Cordiero, P. and Giacobbe, M. (1985), Spontaneous and scientific concepts: Young children's learning of punctuation. In Wells, G. and Nichols, J. (eds) Language and Learning: An Interactional Perspective (pp.107-123). Falmer Books, Brighton.

Cordiero, P (1988) Children's punctuation: An analysis of errors in period placement. Research in the Teaching of English 22 (1), 62-74

Crystal, D. (1995) The Cambridge Encyclopaedia of the English Language. Cambridge University Press. Cambridge.

Department for Education and Employment (1998) The National Literacy Strategy: Framework for Teaching. DfEE, London.

Department for Education and Employment (1999) English: The National Curriculum for England Key Stages 1-4. DfEE, London.

Edelsky, C. (1983) Segmentation and punctuation. Developmental data from young writers in a bilingual program. Research in the Teaching of English 17(2), 135-56

Flower, L. and Hayes, J. (1981) A Cognitive Process Theory of Writing. College Composition and Communication. Vol. 32, pp.365-386

Graves, D.H. (1983) Writing: Teachers and Children at Work. Heinemann Educational Books, New Hampshire and London. 
Hall, N. and Robinson, A. (1996) (Eds) Learning about Punctuation. Multilingual Matters Clevedon, England.

Hall, N. (1998) Young children and resistance to punctuation. Research in Education No.60, Nov 98, 29-39

Harpin, W. (1976). The Second 'R': Writing Development in the Junior School. Allen and Unwin. London.

Kress, G. (1982) $2^{\text {nd }}$ Edition (1994) Learning to Write. Routledge. London and New York.

Perera, K. (1984) Children's Writing and Reading. Blackwell, Oxford.

Qualifications and Curriculum Authority (1998d) The Grammar Papers. London: QCA DfEE

Qualifications and Curriculum Authority (2001) Marking guidelines for writing. London: QCA DfEE

Quirk, R. (1972) The English Language and images of matter. Oxford University Press. London.

School Curriculum and Assessment Authority in association with The Times (1997) Key Stage 2 English Tests. Official National Test Papers. 1996 Test Papers with Answers. How to prepare for the 1997 tests. HMSO, London.

School Curriculum and Assessment Authority in association with The Times (1998) Key Stage 2 English Tests. Official National Test Papers. 1997 Test Papers with Answers. How to prepare for the 1998 tests. HMSO, London.

Sharples, M. (1999) Writing as Creative Design. Routledge, London and New York.

Shaughnessy, M.P. (1977) Errors and Expectations. O.U.P., New York.

Wilde, S. (1996) Just Periods and Exclamation Points: The Continued Development of Children's Knowledge about Punctuation. In Hall, N. and Robinson, A. (eds) Learning about Punctuation (pp. 64-73). Multilingual Matters, Clevedon, England. 